\title{
Considerations for Defining Cytokine Dose, Duration, and Milieu That Are Appropriate for Modeling Chronic Low-Grade Inflammation in Type 2 Diabetes
}

\author{
Craig S. Nunemaker ${ }^{1,2}$ \\ ${ }^{1}$ Diabetes Institute, Heritage College of Osteopathic Medicine, Ohio University, Athens, OH, USA \\ ${ }^{2}$ Department of Biomedical Sciences, Heritage College of Osteopathic Medicine, Ohio University, Athens, OH, USA \\ Correspondence should be addressed to Craig S. Nunemaker; nunemake@ohio.edu
}

Received 22 July 2016; Accepted 25 September 2016

Academic Editor: Akira Mima

Copyright (C) 2016 Craig S. Nunemaker. This is an open access article distributed under the Creative Commons Attribution License, which permits unrestricted use, distribution, and reproduction in any medium, provided the original work is properly cited.

Proinflammatory cytokines have been implicated in the pathophysiology of both type 1 diabetes (T1D) and type 2 diabetes (T2D). T1D is an autoimmune disease involving the adaptive immune system responding to pancreatic beta-cells as antigen-presenting cells. This attracts immune cells that surround pancreatic islets (insulitis) and secrete cytokines, such as IL-1beta, IFN-gamma, and TNF-alpha, in close proximity to pancreatic beta-cells. In contrast, there is little evidence for such a focused autoimmune response in T2D. Instead, the innate immune system, which responds to cellular damage and pathogens, appears to play a key role. There are three major sources of proinflammatory cytokines that may impact islet/beta-cell function in T2D: (1) from islet cells, (2) from increased numbers of intraislet macrophages/immune cells, and (3) from increased circulating levels of proinflammatory cytokines due to obesity, presumably coming from inflamed adipose tissue. These differences between T1D and T2D are reflected by significant differences in the cytokine concentration, duration, and milieu. This review focuses on chronic versus acute cytokine action, cytokine concentrations, and cytokine milieu from the perspective of the pancreatic islet in T2D. We conclude that new cytokine models may be needed to reflect the pathophysiology of T2D more effectively than what are currently employed.

\section{Introduction}

Nearly a century has passed since insulin codiscoverers Frederick Banting and Charles Best observed the first patient to receive insulin therapy in 1922, instantly transforming the prognosis of type 1 diabetes (T1D) from a death sentence to a manageable disease. However, the root cause of T1D is still not known, but the processes that lead to the destruction of insulin-producing pancreatic beta-cells have been fairly well elucidated. T1D is now considered an autoimmune disease that causes the gradual, systematic destruction of pancreatic beta-cells within the islets of Langerhans. Proinflammatory cytokines play a prominent role in the pathophysiology of T1D [1-6], but increasing evidence also suggests a significant role for cytokines in islet dysfunction in T2D as well [68]. In this review, I address the substantial differences in the inflammatory environment of the pancreatic islet in T1D versus $\mathrm{T} 2 \mathrm{D}$ and then consider alternative models of cytokine exposure that may more accurately reflect the pancreatic environment in $\mathrm{T} 2 \mathrm{D}$, with particular emphasis on the islet.

\section{Cytokines in T1D versus T2D}

There are notable similarities and differences in the action of cytokines in the development of T1D versus T2D $[9,10]$, as shown in Figure 1 and described below. In T1D, beta-cells are the direct target of an autoimmune invasion beginning with peri-insulitis and ending in beta-cell death [10-12]. In T2D, metabolic stress is thought to activate the innate immune system, resulting in a chronic inflammatory state marked by increased cytokines, increased islet-associated macrophages, and beta-cell apoptosis $[10,13,14]$. In T1D, autoimmunity is the prime effector of beta-cell destruction. In $\mathrm{T} 2 \mathrm{D}$, a number of metabolic stress factors related to excess nutrients are thought to contribute to beta-cell decline and 


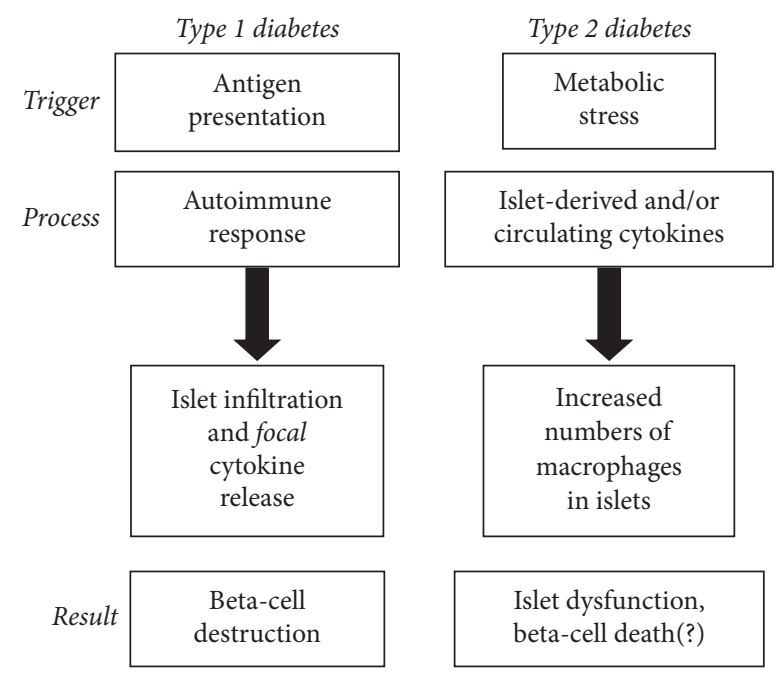

FIGURE 1: A flowchart of very basic differences in the pathophysiology of T1D and T2D. Each disease is described by the immune-mediated triggers, processes, and results with respect to the pancreatic beta-cell/islet.

destruction including glucotoxicity [15-17], lipotoxicity [1517], oxidative stress $[16,18]$, endoplasmic reticulum (ER) stress [19, 20], amyloid deposition [21], and inflammation $[8,13]$. Some evidence suggests that all of these factors may even be connected through inflammasome activation [2224]. To bring this discussion full circle, emerging research suggests that some of the putative factors causing beta-cell dysfunction in T2D, most notably ER stress and/or oxidative stress, may play a role in antigen presentation to trigger the autoimmune response in T1D [25-27].

The key proinflammatory cytokines in T1D are interleukin- (IL-) lbeta, tumor necrosis factor alpha (TNF-alpha), and interferon-gamma (IFN-gamma). IL-1beta is produced by monocytes (leukocytes), macrophages, and other immune cells. TNF-alpha is produced by macrophages, lymphoid, stromal cells, and many other cell types and can exist in membrane-bound as well as in soluble forms [28, 29]. IFNgamma is primarily produced by natural killer cells and certain types of $\mathrm{T}$ cells [30], although macrophages can also produce IFN-gamma under certain conditions, such as exposure to IL-12 and IL-18 [31, 32]. Infiltrating immune cells are thought to secrete these three cytokines in close proximity to the beta-cell at high concentrations in T1D, and these cytokines interact synergistically to inflict cytotoxic effects $[3,33-36]$. Although rodent islets may succumb to high concentrations of any of these cytokines, classic studies demonstrated that combinations of these cytokines produced more consistent cytotoxic effects on human islets $[3,4,34$, $37,38]$. In T2D, the metabolic stress of obesity is thought to elevate cytokine production in adipose tissue [39-43] and other organs to a lesser extent [44], resulting in an overall chronic low-grade inflammatory state. In the next section, key parameters will be examined to define a model of islet exposure to cytokines that may resemble the pancreatic environment more closely during the development of T2D.

\section{Considerations for a Model of Cytokine Action Consistent with T2D}

A number of proinflammatory cytokines are elevated in the general circulation of obese individuals compared to lean individuals, and these increased levels are associated with an increased risk of developing T2D [45-53]. This lowgrade systemic inflammation may also play a direct role in triggering beta-cell dysfunction, particularly in T2D. We have previously reported that cytokines can directly affect aspects of islet function in rodent islets at circulating concentrations in vitro [54-56]. However, these effects, which are primarily related to intracellular calcium handling, do not appear to impact cell death rate or insulin secretion in normal islets [55]. As shown in Figure 2, the "T2D-like" cytokines, in the range of circulating levels in the blood, do not increase cell death or decrease insulin secretion significantly. The "T1Dlike" concentrations of cytokines necessary to induce cell death are at least 50-fold higher than what is observed in lowgrade systemic inflammation in T2D (see also similar published data in [55]). The $5 \mathrm{ng} / \mathrm{mL}$ concentration of IL-1beta commonly found in the literature is 10 times greater than the T1D-like concentration and 500 times greater than the T2Dlike concentration shown in Figure 2. This suggests that the use of high concentrations of death-inducing cytokines is not necessarily appropriate for recreating an islet environment related to T2D. To build an appropriate in vitro model of chronic low-grade inflammation that can reasonably mimic the islet environment in T2D in vivo, several questions must be addressed:

(1) What cytokines and chemokines are elevated in the systemic circulation in obesity and T2D that can negatively impact islet function?

(2) What immune cells are found in or near islets that can secrete cytokines in close proximity?

(3) What cytokines are secreted by islet cells themselves in response to damage or stress?

(4) What concentration and duration of exposure mimic chronic low-grade inflammation?

Each of these considerations is discussed in Sections 3.1-3.4.

3.1. Circulating Cytokines and Chemokines. Circulating levels of several cytokines and chemokines have been identified as potential risk factors for developing T2D, including TNFalpha, C-reactive protein (CRP), monocyte chemoattractant protein-1 (MCP-1), IL-1beta, and IL-6 [45-53]. Chief among these risk factors are IL-1beta and IL-6 [57]. IL-1beta at high enough concentrations can destroy beta-cells $[58,59]$. Antagonizing the actions of IL-lbeta has been shown to have clinical value in partially mitigating the symptoms of T2D [60-63], suggesting that IL-1beta plays a role in the pathophysiology of the disease. Numerous studies have also associated increased levels of IL- 6 with the development of type 2 diabetes [64-67]. However, IL-6 has also been associated with beneficial effects of exercise (reviewed in [68]) and with improving islet function $[69,70]$, resulting 


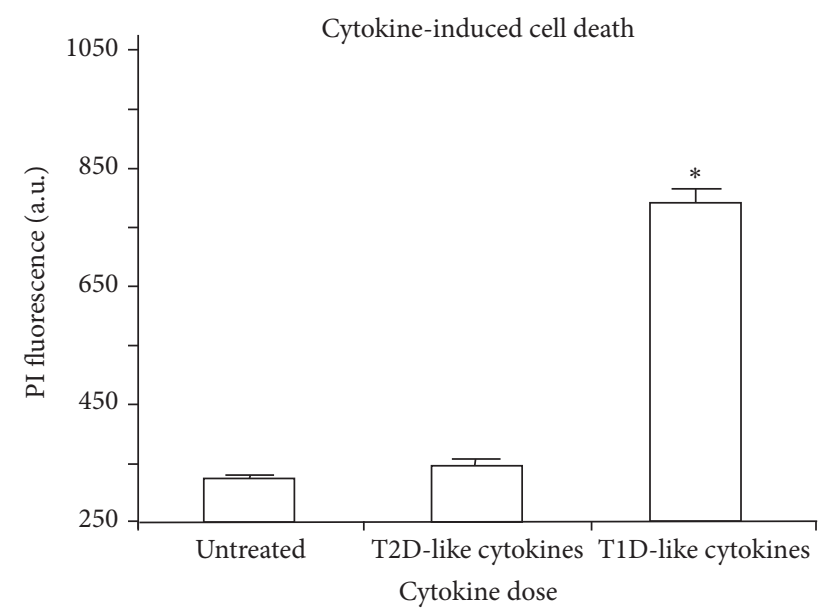

(a)

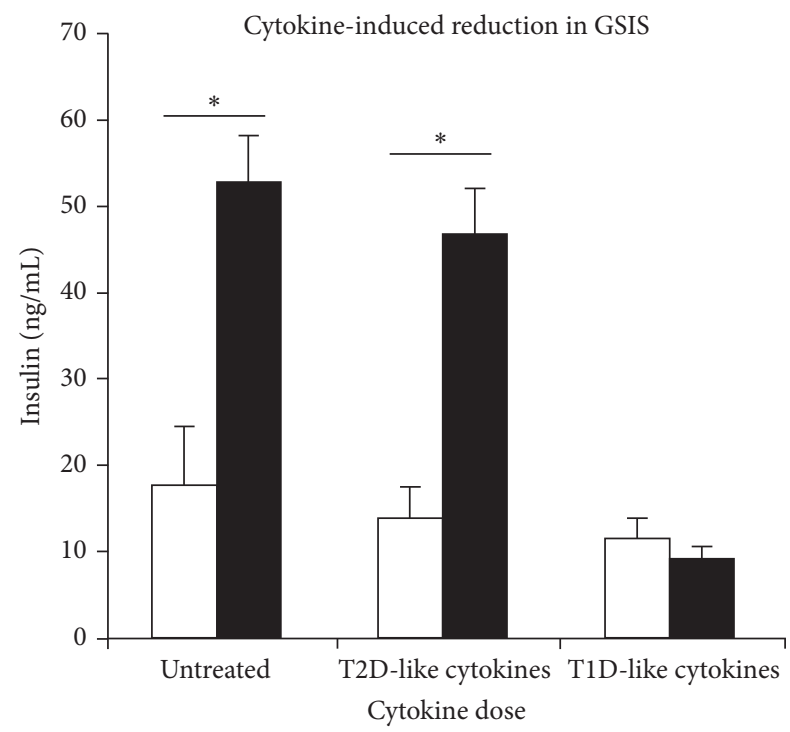

$\square 3 \mathrm{G}$

$28 \mathrm{G}$

(b)

FIGURE 2: Islet viability and function following overnight treatment with different cytokine concentrations. (a) Cell death measurements by propidium iodide (PI) were made on islets following treatment with Roswell Park Memorial Institute 1640 media (untreated), $10 \mathrm{pg} / \mathrm{mL}$ IL-1beta $+20 \mathrm{pg} / \mathrm{mL}$ TNF-alpha $+200 \mathrm{pg} / \mathrm{mL}$ IFNgamma (T2D-like), or $500 \mathrm{pg} / \mathrm{mL}$ IL-lbeta $+1000 \mathrm{pg} / \mathrm{mL}$ TNF-alpha $+10,000 \mathrm{pg} / \mathrm{mL}$ IFN-gamma (T1D-like). (b) Glucose-stimulated insulin secretion (GSIS) in $3 \mathrm{mM}$ glucose (3G, open bars) and $28 \mathrm{mM}$ glucose (28G, filled bars) following cytokine treatments listed in (a). ${ }^{*} P$ value $<0.05$.

in a complex and evolving view over the role(s) of IL-6 in T2D [71-73]. A prospective study focused primarily on links between nutrition and cancer generated an intriguing report that identified the combination of both IL-1beta and IL-6 as key cocontributors to the development of T2D [47]. We reported that serum levels of IL-1beta and IL-6 in diabetesprone mice at an age before hyperglycemia developed were 2-3 times higher than for age-matched heterozygous control mice, suggesting that low-grade systemic inflammation develops early in the disease process [74].

In addition, many other cytokines and chemokines are increased in obesity including leptin, resistin, IL-7, IL-8, retinol binding protein- (RBP-) 4, plasminogen activator inhibitor- (PAI-) 1, chemokine- (C-X-C motif-) ligand 5 (CXCL5), visfatin, chemerin, and vaspin [75, 76]. Other cytokines are decreased with increased obesity including adiponectin, IL-10, and omentin $[75,76]$. We conducted a 32-plex cytokine detection array of mouse blood serum from leptin-receptor-deficient male BKS.Cg-Dock7m+/+ Leprdb/J $(\mathrm{db} / \mathrm{db})$ mice and heterozygous controls at different ages to identify additional cytokines and chemokines [77]. Many of the 32 cytokines tested were above or below the sensitivity for appropriate detection or were highly variable. However, CXCL1 and CXCL5 were increased significantly in serum at the onset of obesity and T2D. We further showed that exposure to circulating concentrations of these chemokines synergistically produced mild inhibition of islet function and that expression of CXCL1 and CXCL5 increased markedly in islets in response to low-grade inflammation [77].

Regarding the classic trio of T1D cytokines, IL-1beta appears to also play a role in T2D, but TNF-alpha and IFNgamma may or may not be as prominent. In our studies, we did not observe elevated serum levels of TNF-alpha in prediabetic mice (IFN-gamma was not examined), and TNFalpha does not appear to have the same degree of impact as IL-1beta and IL-6 on the development of T2D in humans [47]. IFN-gamma appears to be elevated in obesity and may play a role in islet dysfunction in T2D [78, 79]. However, at present there is not sufficient evidence that circulating levels of IFNgamma impact islet function or that IFN-producing immune cells are localized within islets in models of T2D. Additional studies are needed to determine the full milieu of obesityassociated cytokines and the extent to which this milieu of circulating cytokines can impact islet function.

\subsection{Cytokines Produced by Macrophages and Other Immune} Cells within Islets. In addition to the chronic inflammatory state marked by increased circulating cytokines, signs of increased inflammation in T2D have also been observed within the pancreas itself. Specifically, increased numbers of islet-associated macrophages have been reported in rodent models of T2D and in humans with T2D [80, 81]. In the $\mathrm{db} / \mathrm{db}$ mouse model of diabetes, a 4-fold increase in M1 type macrophages was reported as early as 8 weeks of age [82]. Macrophages are involved in adaptation and cellular repair as well as in the discrete removal of dead and dying cells. Thus, increased islet presence of macrophages could merely be an indicator of more dying cells that must be cleared away. However, macrophages could also be active instigators of destruction by secreting various proinflammatory cytokines in close proximity to islet cells. The potential of macrophage instigation of islet dysfunction has been confirmed by studies showing that palmitate causes macrophage accumulation, increased cytokine/chemokine production within islets, and islet dysfunction, but islet dysfunction is prevented when macrophage accumulation is blocked [83, 84]. These 
findings suggest that macrophages play an important role in inflammation caused by metabolic stress. In addition to macrophage involvement, recent work also suggests that clusters of differentiation- (CD-) 45-positive leukocytes are also increased in islets from T2D donors, suggesting a possible role of the adaptive immune system in T2D $[85,86]$.

3.3. Islet-Derived Cytokines. There is also evidence that cells within islets are capable of producing proinflammatory cytokines. Chronic high levels of glucose, for example, can stimulate IL-1beta production in beta-cells [87]. Exposure to certain cytokines can also stimulate islet expression of cytokines and chemokines. For example, treatment with IFN-gamma + TNF-alpha increases islet expression of IL15, interferon-gamma-induced protein- (IP-) 10, CXCL9, CXCL11, and chemokine (C-C motif) ligand- (CCL-) 20 [88]. IL-1beta exposure induces expression of several neutrophilattracting proteins including MCP-1 [89]. Exposure to free fatty acids, palmitate in particular, can induce islet expression of numerous cytokines and chemokines, including IL-1beta, TNF-alpha, IL-6, IL-8, CXCL1, and MCP-1 [83, 84, 90].

The importance of intraislet cytokine production is that cytokine concentrations within islets may be orders of magnitude higher when cytokines are produced by islet cells and/or resident immune cells within the islet in comparison to circulating levels. It should be noted that the increased cytokine expression in many of these studies could not be attributed to any specific cell type(s) within the islet. Thus, it is possible that immune cells within the islet could be responsible for most or all of the increased expression of these cytokines, rather than insulin-producing beta-cells, glucagon-producing alpha cell, or other endocrine cell types in the islet. Thus, intraislet secretion of cytokines, regardless of the source, may markedly increase the potential concentration of cytokine exposure in islet cells.

3.4. Cytokine Dose, Duration, and Milieu. The net effect of cytokine exposure on tissue depends markedly on factors such as cytokine concentration, duration of cytokine exposure, and the combination of cytokines involved (also called the cytokine milieu [91, 92]). IL-1beta, for example, causes islet dysfunction or cell death in a number of studies of chronic exposure $[37,58]$, and blockade of the IL-1 receptor mitigates many of these effects $[60,93,94]$. However, ILlbeta can also enhance insulin secretion [95-97], and recent work even suggests IL-1beta may play a key role in islet compensation for nutrient overload in the early stages of metabolic disorders [98]. In one early series of studies, both positive and negative impacts of IL-lbeta were described based on differences and dose and duration of exposure [99-101]. In the context of T2D, the duration of low-grade inflammation may be a key factor, as cytokines could have compensatory/protective effects initially that become deleterious under chronic conditions. Thus, the dose and duration of cytokine exposure $[98,101,102]$, species being tested [103105], and milieu of interacting cytokines [3, 4, 95, 105, 106] are all important factors that contribute to both positive or negative effects on the beta-cell. In addition, synergistic activity among multiple cytokines can alter or amplify signaling pathways $[3,4,107,108]$, adding an additional layer of complexity to cytokine action.

\section{Cytokine Susceptibility and Signaling in T2D-Prone Islets}

Our recent work has focused on elucidating possible differences in response to chronic low-grade inflammation between islets from diabetes-prone and normal (nondiabetes-prone) environments. Male $\mathrm{db} / \mathrm{db}$ mice and heterozygous controls were used at 4-5 weeks of age, an age at which the capacity for glucose-stimulated insulin secretion and intracellular calcium responses are similar for both mouse strains [74]. The combination of IL-1beta and IL-6 significantly impaired islet function in ways that either alone could not [74]. Further, islets isolated from prediabetic $\mathrm{db} / \mathrm{db}$ mice and exposed in vitro to IL-1beta + IL-6 overnight at approximately circulating levels (in mice) caused a significant decrease in glucose-stimulated insulin secretion, a significant increase in ER stress markers (nitric oxide synthase 2 (NOS2), 78-kDa glucose-regulated protein (GRP78), activating transcription factor 4 (ATF4), and DNA Damage Inducible Transcript 3 (DDIT3), also known as C/EBP homologous protein (CHOP)), and increased cell death; these cytokines produced no such effect in heterozygous control islets [74]. Further, when nondiabetic control mice were implanted with subcutaneous osmotic mini-pumps containing IL-1beta + IL-6 to mimic the serum increases found in prediabetic $\mathrm{db} / \mathrm{db}$ mice, we were able to produce 2-3-fold increases in circulating cytokines, thus reproducing cytokine levels observed in lowgrade inflammation in obesity. The increased circulating levels of IL-1beta + IL-6 were insufficient to impact physiology in these normal mice. When compared with salineimplanted controls, however, isolated islets from cytokinepump mice showed deficiencies in calcium handling and insulin secretion that were similar to cytokine effects on islets in vitro [74]. Finally, these low level cytokine exposures could also impair human islet function [74]. These results in mice suggest that mild increases in circulating cytokines may be sufficient to trigger islet dysfunction leading to islet failure in genetically susceptible individuals [74].

The cytokine signaling pathways may also differ in conditions of low-grade inflammation when compared to classic cytokine cocktails associated with T1D. A microarray study of islet gene expression in response to low concentrations $10 \mathrm{pg} / \mathrm{mL}$ IL-1beta $+20 \mathrm{pg} / \mathrm{mL}$ IL- 6 produced a large number of gene hits that were apparently not associated with canonical signaling pathways for IL-1beta and IL-6 [109]. Several highly cytokine-induced genes related to proteins involved with iron regulation, including Steap4 (six-transmembrane epithelial antigen of prostate 4), lipocalin-2 (Lcn-2), and hepcidin antimicrobial peptide (Hamp). Moreover, seven cytokine-sensitive genes were identified for single nucleotide polymorphisms related to the acute insulin response to glucose (AIRg, a test of islet function) in a genome-wide association scan of a population with a high prevalence 


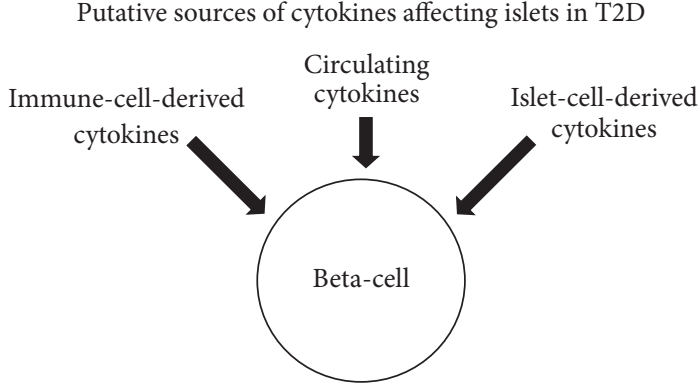

Figure 3: A basic depiction of the putative sources of cytokines affecting islets in T2D.

for T2D [109]. The seven genes were Arap3 (ArfGAP with RhoGAP domain, ankyrin repeat, and PH domain 3), F13al (coagulation factor XIII, A1 polypeptide), Klhl6 (kelch-like protein 6), Nid1 (nidogen 1), Pamrl (peptidase domaincontaining protein associated with muscle regeneration 1), Ripk2 (receptor-interacting protein kinase 2), and Steap4 [109]. These findings suggest novel elements of cytokine signaling that require further study.

\section{Modeling Inflammation in T2D}

The microenvironment of the pancreatic islet during the development of T2D has yet to be fully elucidated. With regard to inflammatory-mediated processes, several sources of proinflammatory cytokines have been suggested throughout this review: (1) immune-cell-derived cytokines from macrophages and lymphocytes, (2) cytokines derived from inflamed fat tissues or other distal sources that increase cytokine concentration in the general circulation, and (3) cytokines/chemokines derived from peptide-producing islet cells such as alpha-cells or beta-cells (see Figure 3). Creating accurate in vitro models of the concentration, duration, and combination of key cytokines involved with each of these sources will contribute greatly toward a better understanding of how islets and other organs such as the liver, muscle, fat, and kidney respond to low-grade inflammation.

We have made a first attempt at a model of the circulating levels of proinflammatory cytokines utilizing IL-lbeta and IL-6. Although the inflammatory environment is dynamic, we focused on cytokines involved prior to the onset of hyperglycemia (the prediabetic stage). Several observations served as our rationale for developing this model of circulating cytokines in T2D. First, the combination of these two cytokines is sufficient to significantly increase the risk of developing T2D in humans [47]. Second, increased levels of IL-1beta and IL- 6 were observed in $\mathrm{db} / \mathrm{db}$ mice prior to hyperglycemia or substantial differences in weight $(<10 \%)$ compared to control mice [74]. Differences in several other cytokines, including TNF-alpha [74], were not observed [77]. Third, exposure to combinations of these cytokines at circulating levels affected islets in unique ways that treatment with individual cytokines could not replicate $[55,74]$. These studies collectively point to the combination of $5-10 \mathrm{pg} / \mathrm{mL}$
IL-1beta and $10-20 \mathrm{pg} / \mathrm{mL}$ IL- 6 as being sufficient to promote islet dysfunction in T2D.

To produce these levels of low-grade systemic inflammation in vivo is quite possible. Osmotic mini-pumps are ideally designed to produce the small and precise changes in the circulating levels of cytokines that define chronic inflammation. We induced low-grade inflammation in vivo in normal healthy mice loading ALZET osmotic mini-pumps (model $1007 \mathrm{~d}$, rate $0.5 \mu \mathrm{L} / \mathrm{h}$ for 7 days) with $32 \mu \mathrm{g} / \mathrm{mL}$ for IL$1 \mathrm{~B}$ plus $4 \mu \mathrm{g} / \mathrm{mL}$ for IL-6 in saline or saline only controls. We inserted each pump subcutaneously into an incision at the nape of the neck to cause low-grade inflammation in mice without significantly impacting blood glucose or insulin levels. ELISA assays confirmed that serum levels of IL-1B and IL-6 were approximately doubled in mice treated with cytokine mini-pumps versus saline control pumps. Islets isolated from cytokine-pump-treated mice showed impaired function compared to saline-pump controls. These findings are detailed in [74] and provide a method for elevating specific circulating cytokines related to chronic low-grade inflammation in T2D, independent of obesity.

\section{Final Thoughts}

Differences in susceptibility to cytokine-induced damage between diabetes-prone and nondiabetes-prone islets suggest that certain genetic predispositions may render some individuals much more susceptible to the negative impact of proinflammatory cytokines than others. How many other chronic diseases could play out in this way? The relatively small increases in circulating cytokines caused by obesity or other chronic inflammatory conditions could conceivably contribute to a plethora of conditions including asthma [110, 111], rheumatoid arthritis [112], heart disease [113], various cancers [114-116], polycystic ovarian syndrome [117, 118], and even mood disorders [119]. Thus, the combination of the genetic predisposition of the individual and the dose, duration, and milieu of cytokine exposure may significantly contribute to numerous chronic diseases.

\section{Competing Interests}

The author declares that there is no conflict of interests regarding the publication of this paper.

\section{Acknowledgments}

This work was supported by NIDDK R01 089182 and the Diabetes Institute and Heritage College of Osteopathic Medicine at Ohio University. Special thanks are due to Catherine Hajmrle and Patrick E. MacDonald for stimulating the genesis of this review and to Karie Cook for editing. Thanks are due to Stacey Dula and Kathryn Corbin for data related to Figure 2. 


\section{References}

[1] T. Mandrup-Poulsen, K. Bendtzen, J. H. Nielsen, G. Bendixen, and J. Nerup, "Cytokines cause functional and structural damage to isolated islets of Langerhans," Allergy, vol. 40, no. 6, pp. 424-429, 1985.

[2] K. Bendtzen, T. Mandrup-Poulsen, J. Nerup, J. H. Nielsen, C. A. Dinarello, and M. Svenson, "Cytotoxicity of human pI 7 Interleukin-1 for pancreatic islets of Langerhans," Science, vol. 232, no. 4757, pp. 1545-1547, 1986.

[3] C. Pukel, H. Baquerizo, and A. Rabinovitch, "Destruction of rat islet cell monolayers by cytokines. Synergistic interactions of interferon-gamma, tumor necrosis factor, lymphotoxin, and interleukin 1," Diabetes, vol. 37, no. 1, pp. 133-136, 1988.

[4] J. A. Corbett, M. A. Sweetland, J. L. Wang, J. R. Lancaster Jr., and M. L. McDaniel, "Nitric oxide mediates cytokine-induced inhibition of insulin secretion by human islets of Langerhans," Proceedings of the National Academy of Sciences of the United States of America, vol. 90, no. 5, pp. 1731-1735, 1993.

[5] A. Rabinovitch and W. L. Suarez-Pinzon, "Cytokines and their roles in pancreatic islet $\beta$-cell destruction and insulindependent diabetes mellitus," Biochemical Pharmacology, vol. 55, no. 8, pp. 1139-1149, 1998.

[6] J. W. Ramadan, S. R. Steiner, C. M. O’Neill, and C. S. Nunemaker, "The central role of calcium in the effects of cytokines on beta-cell function: implications for type 1 and type 2 diabetes," Cell Calcium, vol. 50, no. 6, pp. 481-490, 2011.

[7] A. S. Greenberg and M. L. McDaniel, "Identifying the links between obesity, insulin resistance and $\beta$-cell function: potential role of adipocyte-derived cytokines in the pathogenesis of type 2 diabetes," European Journal of Clinical Investigation, vol. 32, no. 3, pp. 24-34, 2002.

[8] G. S. Hotamisligil, "Inflammation and metabolic disorders," Nature, vol. 444, no. 7121, pp. 860-867, 2006.

[9] M. Y. Donath, J. Størling, K. Maedler, and T. Mandrup-Poulsen, "Inflammatory mediators and islet $\beta$-cell failure: a link between type 1 and type 2 diabetes," Journal of Molecular Medicine, vol. 81, no. 8, pp. 455-470, 2003.

[10] M. Cnop, N. Welsh, J.-C. Jonas, A. Jörns, S. Lenzen, and D. L. Eizirik, "Mechanisms of pancreatic $\beta$-cell death in type 1 and type 2 diabetes: many differences, few similarities," Diabetes, vol. 54, no. 2, pp. S97-S107, 2005.

[11] D. L. Eizirik, M. L. Colli, and F. Ortis, "The role of inflammation in insulitis and $\beta$-cell loss in type 1 diabetes," Nature Reviews Endocrinology, vol. 5, no. 4, pp. 219-226, 2009.

[12] R. Bergholdt, P. Heding, K. Nielsen et al., "Type 1 database mellitus: an inflammatory disease of the islet," Advances in Experimental Medicine and Biology, vol. 552, pp. 129-153, 2004.

[13] M. Y. Donath, M. Böni-Schnetzler, H. Ellingsgaard, and J. A. Ehses, "Islet inflammation impairs the pancreatic $\beta$-cell in type 2 diabetes," Physiology, vol. 24, no. 6, pp. 325-331, 2009.

[14] J. A. Ehses, M. Böni-Schnetzler, M. Faulenbach, and M. Y. Donath, "Macrophages, cytokines and $\beta$-cell death in Type 2 diabetes," Biochemical Society Transactions, vol. 36, no. 3, pp. 340-342, 2008.

[15] V. Poitout and R. P. Robertson, "Minireview: secondary $\beta$-cell failure in type 2 diabetes-a convergence of glucotoxicity and lipotoxicity," Endocrinology, vol. 143, no. 2, pp. 339-342, 2002.

[16] R. P. Robertson, J. Harmon, P. O. T. Tran, and V. Poitout, “ $\beta$ cell glucose toxicity, lipotoxicity, and chronic oxidative stress in type 2 diabetes," Diabetes, vol. 53, no. 1, pp. S119-S124, 2004.
[17] V. Poitout, "Glucolipotoxicity of the pancreatic $\beta$-cell: myth or reality?” Biochemical Society Transactions, vol. 36, no. 5, pp. 901904, 2008.

[18] M. R. Duchen, "Roles of mitochondria in health and disease," Diabetes, vol. 53, no. 1, pp. S96-S102, 2004.

[19] E. Araki, S. Oyadomari, and M. Mori, "Endoplasmic reticulum stress and diabetes mellitus," Internal Medicine, vol. 42, no. 1, pp. 7-14, 2003.

[20] D. L. Eizirik, A. K. Cardozo, and M. Cnop, "The role for endoplasmic reticulum stress in diabetes mellitus," Endocrine Reviews, vol. 29, no. 1, pp. 42-61, 2008.

[21] L. Haataja, T. Gurlo, C. J. Huang, and P. C. Butler, "Islet amyloid in type 2 diabetes, and the toxic oligomer hypothesis," Endocrine Reviews, vol. 29, no. 3, pp. 303-316, 2008.

[22] K. Schroder, R. Zhou, and J. Tschopp, “The NLRP3 inflammasome: a sensor for metabolic danger?” Science, vol. 327, no. 5963, pp. 296-300, 2010.

[23] S. L. Masters, A. Dunne, S. L. Subramanian et al., "Activation of the NLRP3 inflammasome by islet amyloid polypeptide provides a mechanism for enhanced IL-1 $\beta 2$ in type 2 diabetes," Nature Immunology, vol. 11, no. 10, pp. 897-904, 2010.

[24] B. Vandanmagsar, Y.-H. Youm, A. Ravussin et al., “The NLRP3 inflammasome instigates obesity-induced inflammation and insulin resistance," Nature Medicine, vol. 17, no. 2, pp. 179-188, 2011.

[25] S. A. Tersey, Y. Nishiki, A. T. Templin et al., "Islet $\beta$-cell endoplasmic reticulum stress precedes the onset of type 1 diabetes in the nonobese diabetic mouse model," Diabetes, vol. 61, no. 4, pp. 818-827, 2012.

[26] Y. Imai, A. D. Dobrian, M. A. Morris, and J. L. Nadler, "Islet inflammation: a unifying target for diabetes treatment?" Trends in Endocrinology and Metabolism, vol. 24, no. 7, pp. 351-360, 2013.

[27] A. Maganti, C. Evans-Molina, and R. Mirmira, "From immunobiology to $\beta$-cell biology: the changing perspective on type 1 diabetes," Islets, vol. 6, no. 2, Article ID e28778, 2014.

[28] K. Pfeffer, "Biological functions of tumor necrosis factor cytokines and their receptors," Cytokine and Growth Factor Reviews, vol. 14, no. 3-4, pp. 185-191, 2003.

[29] A. V. Tumanov, S. I. Grivennikov, A. A. Kruglov et al., "Cellular source and molecular form of TNF specify its distinct functions in organization of secondary lymphoid organs," Blood, vol. 116, no. 18 , pp. 3456-3464, 2010.

[30] J. R. Schoenborn and C. B. Wilson, "Regulation of interferon$\gamma$ during innate and adaptive immune responses," Advances in Immunology, vol. 96, pp. 41-101, 2007.

[31] M. Munder, M. Mallo, K. Eichmann, and M. Modolell, "Murine macrophages secrete interferon $\gamma$ upon combined stimulation with interleukin (IL)-12 and IL-18: a novel pathway of autocrine macrophage activation," Journal of Experimental Medicine, vol. 187, no. 12, pp. 2103-2108, 1998.

[32] L. Darwich, G. Coma, R. Peña et al., "Secretion of interferon$\gamma$ by human macrophages demonstrated at the single-cell level after costimulation with interleukin (IL)-12 plus IL-18," Immunology, vol. 126, no. 3, pp. 386-393, 2009.

[33] A. Rabinovitch, "An update on cytokines in the pathogenesis of insulin-dependent diabetes mellitus," Diabetes/Metabolism Reviews, vol. 14, no. 2, pp. 129-151, 1998.

[34] T. Mandrup-Poulsen, K. Bendtzen, C. A. Dinarello, and J. Nerup, "Human tumor necrosis factor potentiates human interleukin 1-mediated rat pancreatic $\beta$-cell cytotoxicity," The Journal of Immunology, vol. 139, no. 12, pp. 4077-4082, 1987. 
[35] I. L. Campbell, A. Iscaro, and L. C. Harrison, "IFN- $\gamma$ and tumor necrosis factor- $\alpha$ : cytotoxicity to murine islets of Langerhans," Journal of Immunology, vol. 141, no. 7, pp. 2325-2329, 1988.

[36] M. R. Heitmeier, A. L. Scarim, and J. A. Corbett, "Interferon$\gamma$ increases the sensitivity of islets of langerhans for inducible nitric-oxide synthase expression induced by interleukin 1," The Journal of Biological Chemistry, vol. 272, no. 21, pp. 13697-13704, 1997.

[37] A. Rabinovitch, W. Sumoski, R. V. Rajotte, and G. L. Warnock, "Cytotoxic effects of cytokines on human pancreatic islet cells in monolayer culture," The Journal of Clinical Endocrinology \& Metabolism, vol. 71, no. 1, pp. 152-156, 1990.

[38] G. Soldevila, M. Buscema, M. Doshi, R. F. L. James, G. F. Bottazzo, and R. Pujol-Borrell, "Cytotoxic effect of IFN- $\gamma$ plus TNF- $\alpha$ on human islet cells," Journal of Autoimmunity, vol. 4, no. 2, pp. 291-306, 1991.

[39] Y.-H. Lee and R. E. Pratley, “The evolving role of inflammation in obesity and the metabolic syndrome," Current Diabetes Reports, vol. 5, no. 1, pp. 70-75, 2005.

[40] G. Fantuzzi, "Adipose tissue, adipokines, and inflammation," Journal of Allergy and Clinical Immunology, vol. 115, no. 5, pp. 911-920, 2005.

[41] A. S. Greenberg and M. S. Obin, "Obesity and the role of adipose tissue in inflammation and metabolism," American Journal of Clinical Nutrition, vol. 83, no. 2, pp. 461S-465S, 2006.

[42] B. Gustafson, "Adipose tissue, inflammation and atherosclerosis," Journal of Atherosclerosis and Thrombosis, vol. 17, no. 4, pp. 332-341, 2010.

[43] K. A. Harford, C. M. Reynolds, F. C. McGillicuddy, and H. M. Roche, "Fats, inflammation and insulin resistance: insights to the role of macrophage and T-cell accumulation in adipose tissue," Proceedings of the Nutrition Society, vol. 70, no. 4, pp. 408-417, 2011.

[44] M. Arnush, M. R. Heitmeier, A. L. Scarim, M. H. Marino, P. T. Manning, and J. A. Corbett, "IL-1 produced and released endogenously within human islets inhibits $\beta$ cell function," Journal of Clinical Investigation, vol. 102, no. 3, pp. 516-526, 1998.

[45] A. D. Pradhan, J. E. Manson, N. Rifai, J. E. Buring, and P. M. Ridker, "C-reactive protein, interleukin 6, and risk of developing type 2 diabetes mellitus," The Journal of the American Medical Association, vol. 286, no. 3, pp. 327-334, 2001.

[46] F. B. Hu, J. B. Meigs, T. Y. Li, N. Rifai, and J. E. Manson, "Inflammatory markers and risk of developing type 2 diabetes in women," Diabetes, vol. 53, no. 3, pp. 693-700, 2004.

[47] J. Spranger, A. Kroke, M. Möhlig et al., "Inflammatory cytokines and the risk to develop type 2 diabetes: Results of the prospective population-based European Prospective Investigation into Cancer and Nutrition (EPIC)-Potsdam study," Diabetes, vol. 52, no. 3, pp. 812-817, 2003.

[48] B. Vozarova, C. Weyer, R. S. Lindsay, R. E. Pratley, C. Bogardus, and P. A. Tataranni, "High white blood cell count is associated with a worsening of insulin sensitivity and predicts the development of type 2 diabetes," Diabetes, vol. 51, no. 2, pp. 455-461, 2002.

[49] K. E. Wellen and G. S. Hotamisligil, "Inflammation, stress, and diabetes," The Journal of Clinical Investigation, vol. 115, no. 5, pp. 1111-1119, 2005.

[50] J.-M. Fernández-Real, "Genetic predispositions to low-grade inflammation and type 2 diabetes," Diabetes Technology and Therapeutics, vol. 8, no. 1, pp. 55-66, 2006.
[51] K. I. Alexandraki, C. Piperi, P. D. Ziakas et al., "Cytokine secretion in long-standing diabetes mellitus type 1 and 2: associations with low-grade systemic inflammation," Journal of Clinical Immunology, vol. 28, no. 4, pp. 314-321, 2008.

[52] K. Alexandraki, C. Piperi, C. Kalofoutis, J. Singh, A. Alaveras, and A. Kalofoutis, "Inflammatory process in type 2 diabetes: the role of cytokines," Annals of the New York Academy of Sciences, vol. 1084, pp. 89-117, 2006.

[53] H. Kolb and T. Mandrup-Poulsen, "The global diabetes epidemic as a consequence of lifestyle-induced low-grade inflammation," Diabetologia, vol. 53, no. 1, pp. 10-20, 2010.

[54] P. Jahanshahi, R. Wu, J. D. Carter, and C. S. Nunemaker, "Evidence of diminished glucose stimulation and endoplasmic reticulum function in nonoscillatory pancreatic islets," Endocrinology, vol. 150, no. 2, pp. 607-615, 2009.

[55] S. B. Dula, M. Jecmenica, R. Wu et al., "Evidence that lowgrade systemic inflammation can induce islet dysfunction as measured by impaired calcium handling," Cell Calcium, vol. 48, no. 2-3, pp. 133-142, 2010.

[56] K. L. Corbin, T. E. Hall, R. Haile, and C. S. Nunemaker, "A novel fluorescence imaging approach for comparative measurements of pancreatic islet function in vitro," Islets, vol. 3, no. 1, pp. 14-20, 2011.

[57] V. Wieser, A. R. Moschen, and H. Tilg, "Inflammation, cytokines and insulin resistance: a clinical perspective," Archivum Immunologiae et Therapiae Experimentalis, vol. 61, no. 2, pp. 119-125, 2013.

[58] T. Mandrup-Poulsen, G. A. Spinas, S. J. Prowse et al., "Islet cytotoxicity of interleukin 1 . Influence of culture conditions and islet donor characteristics," Diabetes, vol. 36, no. 5, pp. 641-647, 1987.

[59] C. A. Dinarello, M. Y. Donath, and T. Mandrup-Poulsen, "Role of IL-1 $\beta$ in type 2 diabetes," Current Opinion in Endocrinology, Diabetes and Obesity, vol. 17, no. 4, pp. 314-321, 2010.

[60] C. M. Larsen, M. Faulenbach, A. Vaag et al., "Interleukin1-receptor antagonist in type 2 diabetes mellitus," The New England Journal of Medicine, vol. 356, no. 15, pp. 1517-1526, 2007.

[61] A. B. Goldfine, R. Silver, W. Aldhahi et al., "Use of salsalate to target inflammation in the treatment of insulin resistance and type 2 diabetes," Clinical and Translational Science, vol. 1, no. 1, pp. 36-43, 2008.

[62] A. Schwarznau, M. S. Hanson, J. M. Sperger et al., "IL$1 \beta$ receptor blockade protects islets against pro-inflammatory cytokine induced necrosis and apoptosis," Journal of Cellular Physiology, vol. 220, no. 2, pp. 341-347, 2009.

[63] M. Y. Donath, "Targeting inflammation in the treatment of type 2 diabetes," Diabetes, Obesity and Metabolism, vol. 15, no. 3, pp. 193-196, 2013.

[64] B. B. Duncan, M. I. Schmidt, J. S. Pankow et al., "Low-grade systemic inflammation and the development of type 2 diabetes: the atherosclerosis risk in communities study," Diabetes, vol. 52, no. 7, pp. 1799-1805, 2003.

[65] T. Illig, F. Bongardt, A. Schöpfer et al., "Significant association of the interleukin- 6 gene polymorphisms C-174G and A-598G with type 2 diabetes," Journal of Clinical Endocrinology and Metabolism, vol. 89, no. 10, pp. 5053-5058, 2004.

[66] J.-H. Kim, R. A. Bachmann, and J. Chen, "Chapter 21 interleukin-6 and insulin resistance," Vitamins \& Hormones, vol. 80, pp. 613-633, 2009.

[67] E. M. Dahlén, A. Tengblad, T. Länne et al., "Abdominal obesity and low-grade systemic inflammation as markers of subclinical 
organ damage in type 2 diabetes," Diabetes and Metabolism, vol. 40, no. 1, pp. 76-81, 2014.

[68] C. P. Fischer, "Interleukin-6 in acute exercise and training: what is the biological relevance?" Exercise Immunology Review, vol. 12, pp. 6-33, 2006.

[69] S.-E. Choi, K.-M. Choi, I.-H. Yoon et al., "IL-6 protects pancreatic islet beta cells from pro-inflammatory cytokinesinduced cell death and functional impairment in vitro and in vivo," Transplant Immunology, vol. 13, no. 1, pp. 43-53, 2004.

[70] H. Ellingsgaard, J. A. Ehses, E. B. Hammar et al., "Interleukin-6 regulates pancreatic $\alpha$-cell mass expansion," Proceedings of the National Academy of Sciences of the United States of America, vol. 105, no. 35, pp. 13163-13168, 2008.

[71] A. L. Carey and M. A. Febbraio, "Interleukin-6 and insulin sensitivity: friend or foe?" Diabetologia, vol. 47, no. 7, pp. 1135$1142,2004$.

[72] O. P. Kristiansen and T. Mandrup-Poulsen, "Interleukin-6 and diabetes: the good, the bad, or the indifferent?" Diabetes, vol. 54, supplement 2, pp. S114-S124, 2005.

[73] M. Pal, M. A. Febbraio, and M. Whitham, "From cytokine to myokine: the emerging role of interleukin-6 in metabolic regulation," Immunology and Cell Biology, vol. 92, no. 4, pp. 331339, 2014.

[74] C. M. O’Neill, C. Lu, K. L. Corbin et al., "Circulating levels of IL-1B+IL-6 cause ER stress and dysfunction in islets from prediabetic male mice," Endocrinology, vol. 154, no. 9, pp. 30773088, 2013.

[75] K. Makki, P. Froguel, and I. Wolowczuk, "Adipose tissue in obesity-related inflammation and insulin resistance: cells, cytokines, and chemokines," ISRN Inflammation, vol. 2013, Article ID 139239, 12 pages, 2013.

[76] M. K. Piya, P. G. McTernan, and S. Kumar, "Adipokine inflammation and insulin resistance: the role of glucose, lipids and endotoxin," Journal of Endocrinology, vol. 216, no. 1, pp. T1-T15, 2013.

[77] C. S. Nunemaker, H. G. Chung, G. M. Verrilli, K. L. Corbin, A. Upadhye, and P. R. Sharma, "Increased serum CXCL1 and CXCL5 are linked to obesity, hyperglycemia, and impaired islet function," Journal of Endocrinology, vol. 222, no. 2, pp. 267-276, 2014.

[78] R. W. O’Rourke, A. E. White, M. D. Metcalf et al., "Systemic inflammation and insulin sensitivity in obese IFN- $\gamma$ knockout mice," Metabolism, vol. 61, no. 8, pp. 1152-1161, 2012.

[79] F. M. Wensveen, S. Valentić, M. Šestan, T. Turk Wensveen, and B. Polić, "The 'Big Bang' in obese fat: events initiating obesityinduced adipose tissue inflammation," European Journal of Immunology, vol. 45, no. 9, pp. 2446-2456, 2015.

[80] J. A. Ehses, A. Perren, E. Eppler et al., "Increased number of islet-associated macrophages in type 2 diabetes," Diabetes, vol. 56, no. 9, pp. 2356-2370, 2007.

[81] M. Böni-Schnetzler, J. A. Ehses, M. Faulenbach, and M. Y. Donath, "Insulitis in type 2 diabetes," Diabetes, Obesity and Metabolism, vol. 10, no. 4, pp. 201-204, 2008.

[82] H. Cucak, L. G. Grunnet, and A. Rosendahl, "Accumulation of M1-like macrophages in type 2 diabetic islets is followed by a systemic shift in macrophage polarization," Journal of Leukocyte Biology, vol. 95, no. 1, pp. 149-160, 2014.

[83] K. Eguchi, I. Manabe, Y. Oishi-Tanaka et al., "Saturated fatty acid and TLR signaling link $\beta$ cell dysfunction and islet inflammation," Cell Metabolism, vol. 15, no. 4, pp. 518-533, 2012.
[84] K. Eguchi and I. Manabe, "Macrophages and islet inflammation in type 2 diabetes," Diabetes, Obesity and Metabolism, vol. 15, no. 3, pp. 152-158, 2013.

[85] M. J. Butcher, D. Hallinger, E. Garcia et al., "Association of proinflammatory cytokines and islet resident leucocytes with islet dysfunction in type 2 diabetes," Diabetologia, vol. 57 , no. 3, pp. 491-501, 2014.

[86] C. Westwell-Roper and J. A. Ehses, "Is there a role for the adaptive immune system in pancreatic beta cell failure in type 2 diabetes?” Diabetologia, vol. 57, no. 3, pp. 447-450, 2014.

[87] K. Maedler, P. Sergeev, F. Ris et al., "Glucose-induced $\beta$ cell production of IL- $1 \beta$ contributes to glucotoxicity in human pancreatic islets," The Journal of Clinical Investigation, vol. 110, no. 6, pp. 851-860, 2002.

[88] A. K. Cardozo, P. Proost, C. Gysemans, M.-C. Chen, C. Mathieu, and D. L. Eizirik, "IL- $1 \beta$ and IFN- $\gamma$ induce the expression of diverse chemokines and IL-15 in human and rat pancreatic islet cells, and in islets from pre-diabetic NOD mice," Diabetologia, vol. 46, no. 2, pp. 255-266, 2003.

[89] M.-C. Chen, E. Schuit, and D. L. Eizirik, "Identification of IL$1 \beta$-induced messenger RNAs in rat pancreatic beta cells by differential display of messenger RNA," Diabetologia, vol. 42, no. 10, pp. 1199-1203, 1999.

[90] M. Igoillo-Esteve, L. Marselli, D. A. Cunha et al., "Palmitate induces a pro-inflammatory response in human pancreatic islets that mimics CCL2 expression by beta cells in type 2 diabetes," Diabetologia, vol. 53, no. 7, pp. 1395-1405, 2010.

[91] K. Esposito, F. Nappo, F. Giugliano et al., "Cytokine milieu tends toward inflammation in type 2 diabetes," Diabetes Care, vol. 26, no. 5, p. 1647, 2003.

[92] N. Welsh, M. Cnop, I. Kharroubi et al., "Is there a role for locally produced interleukin-1 in the deleterious effects of high glucose or the type 2 diabetes milieu to human pancreatic islets?" Diabetes, vol. 54, no. 11, pp. 3238-3244, 2005.

[93] N. S. Sauter, F. T. Schulthess, R. Galasso, L. W. Castellani, and K. Maedler, "The antiinflammatory cytokine interleukin-1 receptor antagonist protects from high-fat diet-induced hyperglycemia," Endocrinology, vol. 149, no. 5, pp. 2208-2218, 2008.

[94] C. Westwell-Roper, D. L. Dai, G. Soukhatcheva et al., "IL-1 blockade attenuates islet amyloid polypeptide-induced proinflammatory cytokine release and pancreatic islet graft dysfunction," The Journal of Immunology, vol. 187, no. 5, pp. 2755-2765, 2011.

[95] V. K. Mehta, W. Hao, B. M. Brooks-Worrell, and J. P. Palmer, "Low-dose interleukin 1 and tumor necrosis factor individually stimulate insulin release but in combination cause suppression," European Journal of Endocrinology, vol. 130, no. 2, pp. 208-214, 1994.

[96] D. L. Eizirik, S. Sandler, N. Welsh, L. Juntti-Berggren, and P.O. Berggren, "Interleukin- $\beta$-induced stimulation of insulin release in mouse pancreatic islets is related to diacylglycerol production and protein kinase C activation," Molecular and Cellular Endocrinology, vol. 111, no. 2, pp. 159-165, 1995.

[97] C. Arous, P. G. Ferreira, E. T. Dermitzakis, and P. A. Halban, "Short term exposure of beta cells to low concentrations of interleukin- $1 \beta$ improves insulin secretion through focal adhesion and actin remodeling and regulation of gene expression," Journal of Biological Chemistry, vol. 290, no. 10, pp. 6653-6669, 2015.

[98] C. Hajmrle, N. Smith, A. F. Spigelman et al., "Interleukin-1 signaling contributes to acute islet compensation," JCI Insight, vol. 1, no. 4, Article ID e86055, 2016. 
[99] G. A. Spinas, T. Mandrup-Poulsen, J. Mølvig et al., "Low concentrations of interleukin-1 stimulate and high concentrations inhibit insulin release from isolated rat islets of Langerhans," Acta Endocrinologica, vol. 113, no. 4, pp. 551-558, 1986.

[100] G. A. Spinas, B. S. Hansen, S. Linde et al., "Interleukin 1 dosedependently affects the biosynthesis of (pro)insulin in isolated rat islets of Langerhans," Diabetologia, vol. 30, no. 7, pp. 474480, 1987.

[101] G. A. Spinas, J. P. Palmer, T. Mandrup-Poulsen, H. Andersen, J. H. Nielsen, and J. Nerup, "The bimodal effect of interleukin 1 on rat pancreatic beta-cells-stimulation followed by inhibitiondepends upon dose, duration of exposure, and ambient glucose concentration," Acta Endocrinologica, vol. 119, no. 2, pp. 307-311, 1988.

[102] A. L. Scarim, M. R. Heitmeier, and J. A. Corbett, "Irreversible inhibition of metabolic function and islet destruction after a 36hour exposure to interleukin-1 $\beta$," Endocrinology, vol. 138, no. 12, pp. 5301-5307, 1997.

[103] D. J. Kawahara and J. S. Kenney, "Species differences in human and rat islet sensitivity to human cytokines. Monoclonal antiinterleukin-1 (IL-1) influences on direct and indirect IL-1mediated islet effects," Cytokine, vol. 3, no. 2, pp. 117-124, 1991.

[104] D. L. Eizirik, S. Sandler, N. Welsh et al., "Cytokines suppress human islet function irrespective of their effects on nitric oxide generation," The Journal of Clinical Investigation, vol. 93, no. 5, pp. 1968-1974, 1994.

[105] D. L. Eizirik, D. G. Pipeleers, Z. Ling, N. Welsh, C. Hellerström, and A. Andersson, "Major species differences between humans and rodents in the susceptibility to pancreatic $\beta$-cell injury," Proceedings of the National Academy of Sciences of the United States of America, vol. 91, no. 20, pp. 9253-9256, 1994.

[106] J. A. Corbett, G. Kwon, J. Turk, and M. L. McDaniel, "IL-1 beta induces the coexpression of both nitric oxide synthase and cyclooxygenase by islets of Langerhans: activation of cyclooxygenase by nitric oxide," Biochemistry, vol. 32, no. 50, pp. 13767-13770, 1993.

[107] V. Ablamunits, F. Baranova, T. Mandrup-Poulsen, and J. Nerup, "In vitro inhibition of insulin release by blood mononuclear cells from insulin-dependent diabetic and healthy subjects: synergistic action of IL-1 and TNF," Cell Transplantation, vol. 3, no. 1, pp. 55-60, 1994.

[108] M. Cetkovic-Cvrlje and D. L. Eizirik, "TNF- $\alpha$ and IFN- $\gamma$ potentiate the deleterious effects of IL- $1 \beta$ on mouse pancreatic islets mainly via generation of nitric oxide," Cytokine, vol. 6, no. 4, pp. 399-406, 1994.

[109] P. R. Sharma, A. J. Mackey, E. A. Dejene et al., "An islettargeted genome-wide association scan identifies novel genes implicated in cytokine-mediated islet stress in type 2 diabetes," Endocrinology, vol. 156, no. 9, pp. 3147-3156, 2015.

[110] D. Rastogi, S. M. Canfield, A. Andrade et al., "Obesity-associated asthma in children: a distinct entity," Chest, vol. 141, no. 4, pp. 895-905, 2012.

[111] C. S. Farah and C. M. Salome, "Asthma and obesity: a known association but unknown mechanism," Respirology, vol. 17, no. 3, pp. 412-421, 2012.

[112] C. S. Derdemezis, P. V. Voulgari, A. A. Drosos, and D. N. Kiortsis, "Obesity, adipose tissue and rheumatoid arthritis: coincidence or more complex relationship?" Clinical and Experimental Rheumatology, vol. 29, no. 4, pp. 712-727, 2011.

[113] P. Libby, P. M. Ridker, and G. K. Hansson, "Inflammation in atherosclerosis: from pathophysiology to practice," Journal of the American College of Cardiology, vol. 54, no. 23, pp. 21292138, 2009.

[114] E. K. Lund, N. J. Belshaw, G. O. Elliott, and I. T. Johnson, “Recent advances in understanding the role of diet and obesity in the development of colorectal cancer," Proceedings of the Nutrition Society, vol. 70, no. 2, pp. 194-204, 2011.

[115] A. M. Ryan, M. Duong, L. Healy et al., "Obesity, metabolic syndrome and esophageal adenocarcinoma: epidemiology, etiology and new targets," Cancer Epidemiology, vol. 35, no. 4, pp. 309319, 2011.

[116] G. Sethi, M. K. Shanmugam, L. Ramachandran, A. P. Kumar, and V. Tergaonkar, "Multifaceted link between cancer and inflammation," Bioscience Reports, vol. 32, no. 1, pp. 1-15, 2012.

[117] T. Sathyapalan and S. L. Atkin, "Mediators of inflammation in polycystic ovary syndrome in relation to adiposity," Mediators of Inflammation, vol. 2010, Article ID 758656, 5 pages, 2010.

[118] A. Repaci, A. Gambineri, and R. Pasquali, "The role of lowgrade inflammation in the polycystic ovary syndrome," Molecular and Cellular Endocrinology, vol. 335, no. 1, pp. 30-41, 2011.

[119] J. K. Soczynska, S. H. Kennedy, H. O. Woldeyohannes et al., "Mood disorders and obesity: understanding inflammation as a pathophysiological nexus," NeuroMolecular Medicine, vol. 13, no. 2, pp. 93-116, 2011. 


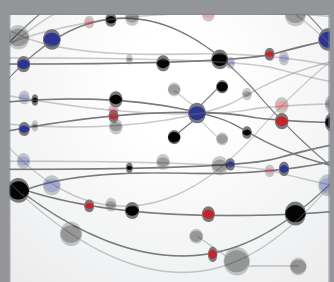

The Scientific World Journal
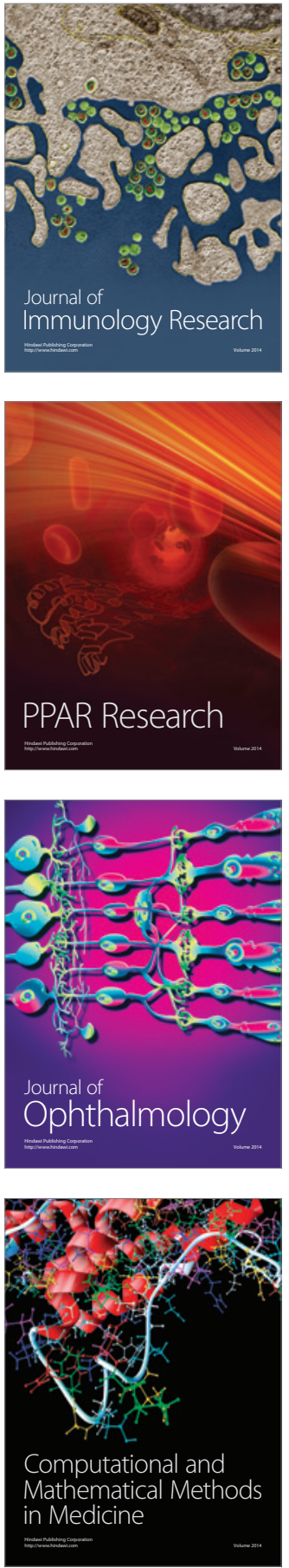

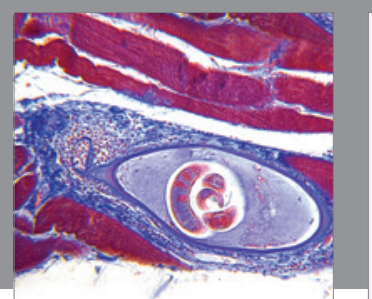

Gastroenterology Research and Practice

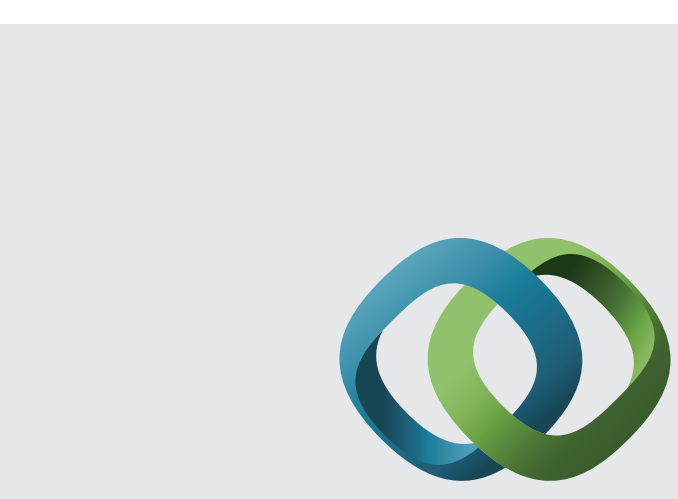

\section{Hindawi}

Submit your manuscripts at

http://www.hindawi.com
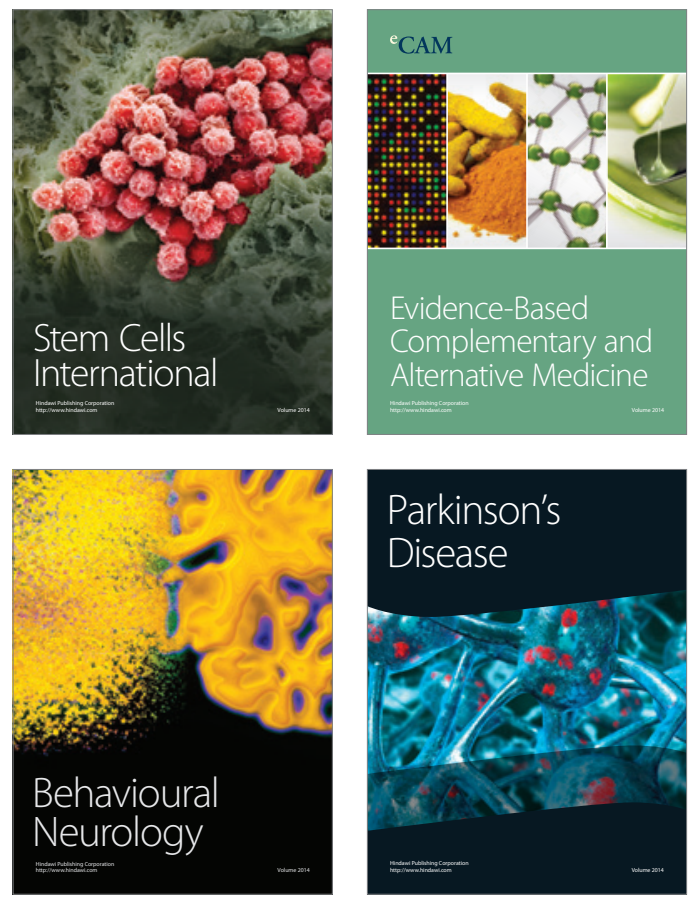
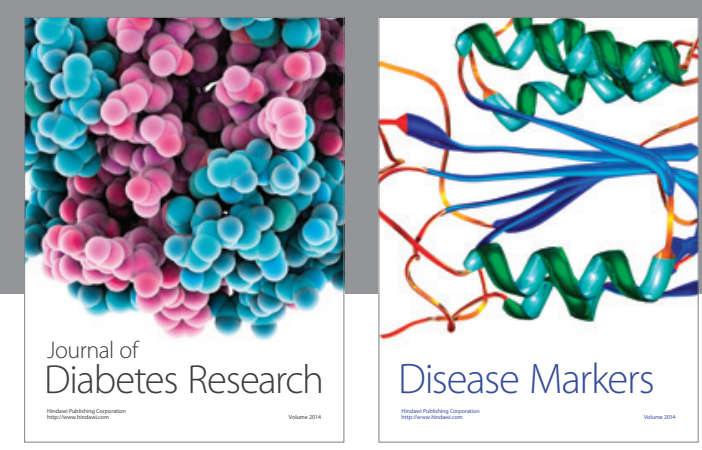

Disease Markers
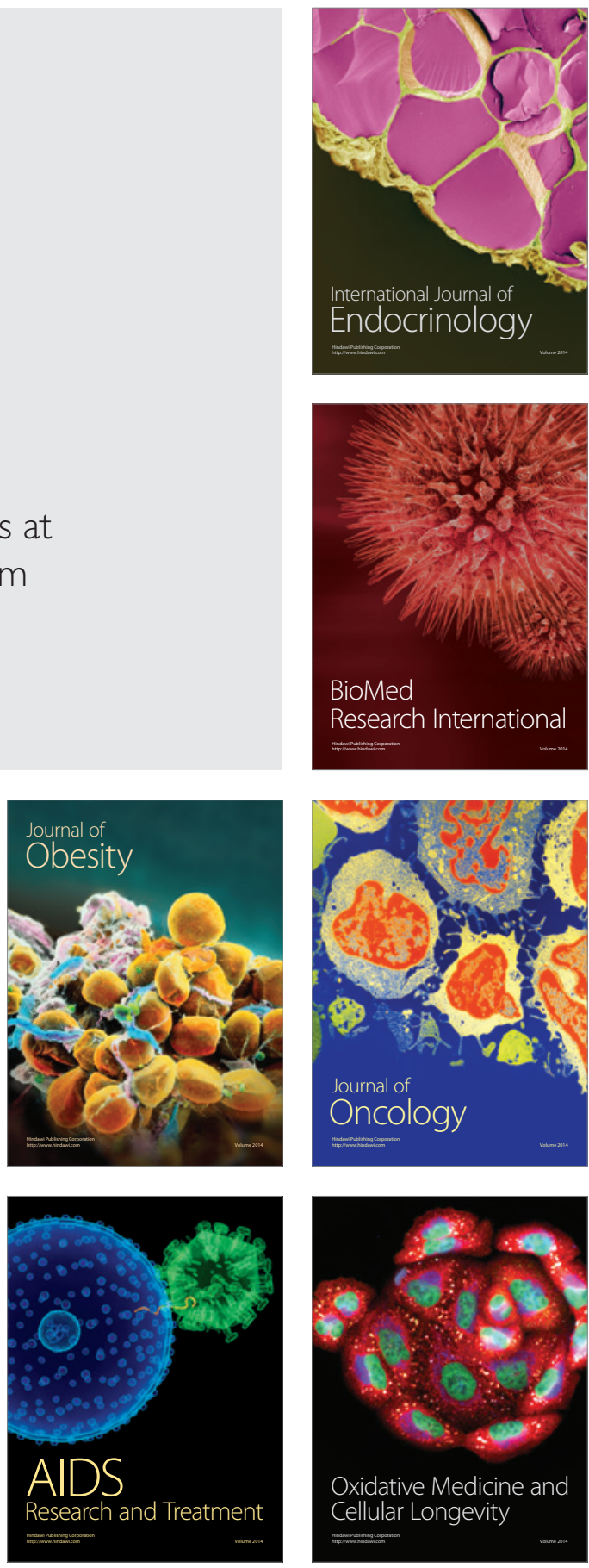